CASE REPORTS

\title{
Fatal dependence on kaolin and morphine mixture
}

\author{
J. M. BARRAGRY* \\ M.D., M.R.C.P. \\ D. V. MORRIS \\ M.B., M.R.C.P. \\ Unit of Metabolism and Endocrinology, The London Hospital Medical College, London, E.1
}

\begin{abstract}
Summary
A patient is described who had a long history of abuse of kaolin and morphine mixture which ultimately proved fatal.
\end{abstract}

\section{Case report}

A 24-year-old female was admitted to hospital with a 2-week history of progressive proximal limb weakness, and pain and fatty dyspepsia for one month. She had recently been taking amylobarbitone and an oral contraceptive, the latter withdrawn one week before admission. She was hypertensive $(180 / 120 \mathrm{mmHg})$, had pitting ankle oedema, erythema and pigmentation of the hands and livido reticularis on the legs. All limb muscle groups were weak and tender but not wasted, with a variable right hemi-hypaesthesia and generalized reduction of tendon reflexes. The abdomen was grossly distended, with a tender mass in the right hypochondrium. Relevant investigations included plasma urea 30 $\mathrm{mg} / \mathrm{dl}$; plasma creatinine $65 \mu \mathrm{mol} / 1$; plasma sodium $137 \mathrm{mmol} / \mathrm{l}$; potassium $1.6 \mathrm{mmol} / 1$; chloride 88 $\mathrm{mmol} / \mathrm{l}$; bicarbonate $32 \mathrm{mmol} / \mathrm{l}$; 24-hr urinary sodium was $112 \mathrm{mmol}$ and potassium $10 \mathrm{mmol}$. Primary hyperaldosteronism was excluded on the basis of plasma renin and aldosterone measurements, and treatment with spironolactone and propranolol was instituted. She became normotensive and normokalaemic and remained so after withdrawal of these compounds. Plasma cortisols, urinary VMA and IVP were normal. Autoantibody screen was negative, serum AST was $111 \mathrm{u} . / 1$ and creatine kinase $1546 \mathrm{u} . / 1$ (normal $<140 \mathrm{u}$./l); an electromyogram and deltoid muscle biopsy were suggestive of dermatomyositis. Corticosteroid therapy resulted in a sustained improvement in muscle strength. At laparotomy, cholecystectomy was performed for a mucocele associated with cholelithiasis. Two weeks later she developed gross gastric dilatation which responded to supportive measures.

\footnotetext{
* Present address: Meath Hospital, Dublin 8, Eire.
}

Two months later she was re-admitted because of 0 recurrent abdominal distension, diarrhoea and 3 . tetany. She was again hypertensive $(180 / 110 \mathrm{mmHg})$, oु oedematous and had rectal prolapse. Plasma sodium $\delta$ was $148 \mathrm{mmol} / 1$, potassium $1.6 \mathrm{mmol} / \mathrm{l}$ and bicarbon- $\omega$ ate $50 \mathrm{mmol} / \mathrm{l}$. She was found to be in possession of $\dot{\infty}$ large quantities of kaolin and morphine mixture

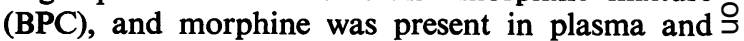
urine samples. On withdrawal of the compound and $\vec{r}$ repletion with potassium she became normotensive 3

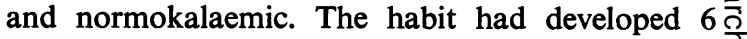
years earlier following an emotional disturbance $\rightarrow$ which resulted in a tendency to diarrhoea. Moge $\varnothing_{\infty}$ recently she would consume in excess of $600 \mathrm{ml}$ \%. the mixture daily. This quantity of kaolin a morphine mixture contains $30 \mathrm{~g}$ sodium bicarbonate, $42 \mathrm{mg}$ anhydrous morphine and $120 \mathrm{~g}$ of light kaolin.

On psychiatric assessment she was thought to have $\stackrel{2}{\unrhd}$ a personality disorder and a number of hospital $\overrightarrow{\vec{P}}$ admissions followed. On each occasion a similar $\frac{\rho}{3}$ clinical picture was seen, and morphine was re- $\bar{T}$ peatedly detected in her urine despite denials of continuing kaolin and morphine ingestion. On one occasion she was found to have ingested large 3 quantities of sodium bicarbonate also. Attempts to $\dot{\sigma}$ discontinue these compounds were unavailing and $\stackrel{3}{3}$. she remained hypertensive and hypokalaemic with $\delta$ gastrointestinal dilatation despite supportive therapy. Eighteen months after initial presentation she 은 collapsed and died. At post-mortem the whole of the $\rightarrow$ gastrointestinal tract was found to contain kaolin and there was evidence of extensive myocardial $\underset{N}{\sim}$ necrosis compatible with prolonged hypokalaemia.

\section{Comment}

Kaolin and morphine mixture may be purchased without prescription and this case illustrates an unusual sequel to its ready availability. Although $\stackrel{\circ}{\odot}$ initially unexplained, the intermittent hypertension $\stackrel{\mathbb{f}}{+}$ and hypokalaemic alkalosis were later considered to 0 reflect the substantial sodium bicarbonate content of $\bar{O}$ kaolin and morphine mixture, later augmented by 
the ingestion of sodium bicarbonate also. The profound hypokalaemia thus induced together with the effects of morphine and kaolin on the intestinal motility were likely causal factors in the development of chronic abdominal distension with ileus and rectal prolapse. It seems improbable that there was any direct association between the muscle disorder and kaolin and morphine abuse. The electromyographic features resembled those of dermatomyositis rather than those previously described in opiate dependence (Weller and Perry, 1973) and this impression was confirmed on muscle biopsy.

\section{References}

Weller, M. \& Perry, R. (1973) Unusual cardiac and neurological reactions to narcotics. Lancet, ii, 799. 